\title{
Unfassbare Intoleranz
}

_ „Ich weiß, ihr seid keine Partnervermittlung“ - so begann eine Nachricht, die wir kürzlich via Facebook von einer Therapeutin erhalten hatten. Sie war auf der Suche nach einer „süßen Physio“, die sie in der Woche zuvor auf einer Fortbildung gesehen hatte und die ihr nicht mehr aus dem Sinn gehen wollte. Uns bat sie, ihr mit einem Facebook-Post bei der Suche zu helfen. So war kurze Zeit später auf unserer Pinnwand zu lesen: „Physio sucht Physio“. Wir waren gespannt, wie dieser ungewöhnliche Post auf Facebook ankommen würde. Die Resonanz war super. Unsere Fans wünschten Glück, drückten Daumen und gaben Tipps, wie die Angebetete noch gefunden werden kann.

_ Doch am nächsten Morgen bat uns die Therapeutin, den Post zu löschen. Sie hatte deswegen in der

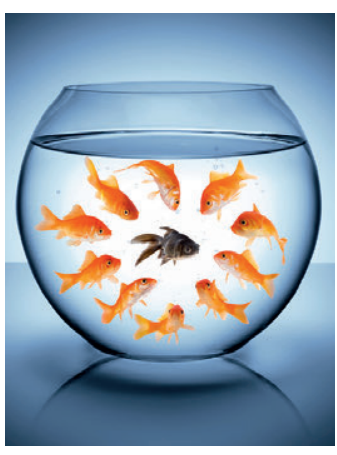
Praxis Ärger bekommen. Durch einen blöden Zufall

hatten ihre Kollegen herausgefunden, dass sie die Suchende ist - und wussten nun auch um ihre Homosexualität. Vier Kollegen hatten sie daraufhin zur Rede gestellt. Uns schrieb sie: „Lesben sind auf Arbeit nicht erwünscht.“ Wir haben den Post natürlich gelöscht. Vergessen konnten wir die Geschichte allerdings bis jetzt nicht. Unfassbar, welch intolerante Menschen es gibt.

- Wir hoffen sehr, dass die Therapeutin die „süße Physio“ noch auf anderem Weg findet. Noch mehr wünschen wir ihr allerdings, dass sie möglichst bald ihre Arbeitsstelle wechseln kann.

Herzliche Grüße

Ihre
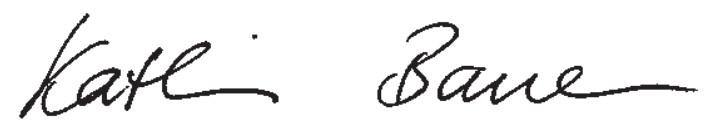

Eingekreist und zur Rede gestellt: Das ist unlängst einer Physiotherapeutin widerfahren, als ihre Kollegen herausfanden, dass sie homosexuell ist.

\section{ZU GEWINNEN}

In jeder physiopraxis werden attraktive Gewinne verlost. Möchten Sie einen ergattern, klicken Sie unter www.thieme.de/physiopraxis auf "Gewinnspiel“.

Und das gibt es in dieser Ausgabe zu gewinnen:

Bücher

3-mal

„Diagnose Epilepsie“ Seite 43 2-mal „Assessments in der Rehabilitation“

Seite 45

und außerdem

1 Entspannungsoase

2 Lenkdrachen

Seite 12

Seite 32 